\title{
Biofilm dynamics characterization using a novel DO-MEA sensor: mass transport and biokinetics
}

\author{
Guimerà Xavier ${ }^{a}$, Moya Ana ${ }^{b, c}$, Dorado Antonio David ${ }^{a}$, Villa Rosa ${ }^{b, c}$, Gabriel David ${ }^{d}$, Gabriel \\ Gemma $^{\text {b,c }}$ and Gamisans Xavier ${ }^{\mathrm{a}, *}$
}

${ }^{a}$ Department of Mining Engineering and atural Resources, Universitat Politècnica de Catalunya, Avinguda de les Bases de Manresa 61-73, 08240 Manresa, Spain

${ }^{b}$ Instituto de Microelectrónica de Barcelona, IMB-CNM (CSIC), Esfera UAB, Campus Universitat Autònoma de Barcelona, 08193 Bellaterra, Barcelona, Spain

${ }^{c}$ Biomedical Research Networking Center in Bioengineering, Biomaterials and Nanomedicine (CIBER$B B N)$, Zaragoza, Spain

${ }^{d}$ Department of Chemical Engineering, Universitat Autònoma de Barcelona, Edifici Q, 08193 Bellaterra, Barcelona, Spain

\begin{abstract}
Biodegradation process modeling is an essential tool for the optimization of biotechnologies related to gaseous pollutants treatment. In these technologies, the predominant role of biofilm, particularly under conditions of no mass transfer limitations, results in a need to determine what processes are occurring within the same. By measuring the interior of the biofilms, an increased knowledge of mass transport and biodegradation processes may be attained. This information is useful in order to develop more reliable models that take biofilm heterogeneity into account. In this study, a new methodology, based on a novel dissolved oxygen (DO) and mass transport microelectronic array (MEA) sensor, is presented in order to characterize a biofilm. Utilizing the MEA sensor, designed to obtain DO and diffusivity profiles with a single measurement, it was possible to obtain distributions of oxygen diffusivity and biokinetic parameters along a biofilm grown in a flat plate bioreactor (FPB). The results obtained for oxygen diffusivity, estimated from oxygenation profiles and direct measurements, revealed that changes in its distribution were reduced when increasing the liquid flow rate. It was also possible to observe the effect of biofilm heterogeneity through biokinetic parameters, estimated using the DO profiles. Biokinetic parameters, including maximum specific growth rate, the Monod half-saturation coefficient of oxygen and the maintenance coefficient for oxygen which showed a marked variation across the biofilm, suggest that a tool that considers the heterogeneity of biofilms is essential for the optimization of biotechnologies.
\end{abstract}




\section{Keywords}

Heterotrophic biofilm; Dissolved Oxygen; Biofilm profiling; MEA sensor; Effective diffusivity; Biokinetic parameters.

\section{Introduction}

Knowledge of biodegradation mechanisms in biofiltration processes (both in biofilters and biotrickling filters) is essential for the development of models and the selection of optimal operating conditions. Model validation has typically been based upon bulk measurements taken in the liquid and gas phases (Kim and Deshusses 2003), due to the impossibility of taking said measurements within the biofilms, where pollutant degradation takes place. The reliability of these models may be enhanced with an increased understanding of biofilms by measuring the different chemical species found within them. Since oxygen is the primary electron acceptor in biological reactions (aerobic conditions), it is one of the most important species to monitor. However, reduced biofilm thickness (ranging from a few microns to a few millimeters) has prevented measurements from being taken within them.

Some of the technical difficulties occurring during the measurement of dissolved oxygen (DO) profiles within biofilms have been resolved thanks to the development of microsensors, with Clark-type microelectrodes being the most commonly used (Revsbech and Jørgensen 1986). Based on the profiles recorded with Clark-type microelectrodes, it has been possible to increase knowledge of biofilm structure (Melo and Frias 2004; Okabe et al. 1999; Zhu et al. 2001) and function (Schramm et al. 1996; Schwermer et al. 2008), and to characterize the mass transport processes and microbial activity occurring across these biofilms. With these profiles, biokinetic parameters commonly computed from microorganisms in suspension (Brouwer et al. 1998), may be replaced by growth parameters extracted from in situ measurements of oxygen profiles within the biofilms (Yurt et al. 2003; Zhou et al. 2012). However, the biokinetic parameters of the attached growth systems are not easily measured, since diffusional resistance within the biofilm occurs simultaneously. Therefore reliable kinetic parameters estimation may be subject to the availability of mass transport information, in addition to other limitations described by Yurt et al. (2003). Mass transport within biofilm is typically considered to occur by diffusional mechanisms, in accordance with Fick’s laws. Although various procedures have been developed to quantify effective diffusivity, the large amount of data required (Chiu et al. 2006; Fu et al. 1994) as well as the need for a specific microsensor (Beyenal et al. 1998; Revsbech et al. 1998) complicates these methods considerably. 
Furthermore, the need for a positioning system (Rosa and Yu 2006), along with its high cost and fragility (Wu et al. 2005) make profile recording with Clark-type microsensors a delicate and tedious process, and one that requires a major investment of both time and resources.

Recently, different microsensors based on micro-electro mechanical system technology (MEMS) have been developed in order to improve microsensor performance in biofilm monitoring (Del Campo et al. 2007; Lee et al. 2007; Liu and Chen 2009). MEMS technology allows for a more versatile design, enabling the fabrication of microelectrodes of different sizes, geometries and arrangements (del Campo et al. 2014; Prehn et al. 2011). In addition, microfabrication techniques allow for cost-effective massproduction of microsensors that may be used for a variety of applications. Microsensors based on MEMS technology have been used to obtain qualitative information on biofilm structure and activity (Godino et al. 2008). With this technology, a novel DO microelectrode array sensor (DO-MEA) was developed to improve biofilm monitoring by recording DO profiles in a single measurement. This sensor consists of a linear gold disk microelectrode array, permitting the recording of $1 \mathrm{~mm}$ DO profiles in a single measurement. The absence of a membrane between the cathode and the measuring medium reduces mass transport resistance, resulting in a faster sensor response. Furthermore, the sensor design allows for the obtaining of mass transport rate profiles through the biofilm.

In this study, the DO-MEA sensor was used to develop an experimental methodology for biofilm characterization. This characterization consisted of obtaining in situ information on mass transport by estimating the biofilm's effective diffusivity, its biokinetics based on microbial growth and maintenance parameters, and its structure through determination of oxygen distribution inside biofilm. Obtained data may be used for model development, taking biofilm heterogeneity into account.

\section{Materials and Methods}

\section{DO-MEA Sensor}

The novel DO-MEA sensor was designed, produced and characterized to obtain DO profiles within biofilms. The sensor (Fig.1) consists of an array of eleven gold disk microelectrodes, having a diameter of $50 \mu \mathrm{m}$, and a gold rectangular macroelectrode along the microdisk array, with a surface area of $2.500 \mathrm{x}$ $0.115 \mathrm{~mm}^{2}$. The eleven small electrodes were designed to serve as working electrodes (WE) while the rectangular one was designed for use as an integrated reference system. 


\section{Sensor microfabrication}

Microsensors were created in clean room facilities at the Barcelona Microelectronics Institute (Spain), using standard photolithography techniques (Bonilla et al. 2011; Gabriel et al. 2007; Guimera et al. 2012).

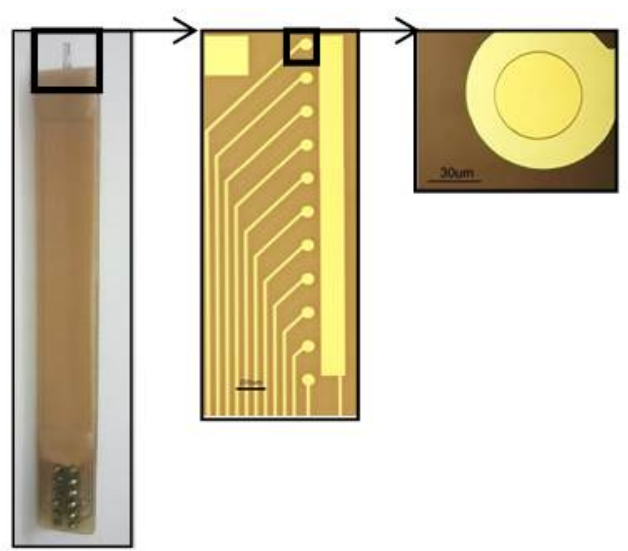

Fig. 1 DO-MEA design of eleven gold disk microelectrodes array and a rectangular macroelectrode with a $500 \mu \mathrm{m}$ thick Pyrex substrate and featuring SU-8 passivation. Complete packaging of the DO-MEA sensor in a PCB using wire bonding.

To summarize, three metal layers were deposited by sputtering over a Pyrex wafer. The first layer consisted of thin titanium $(15 \mathrm{~nm})$ to improve adhesion, a second nickel layer $(15 \mathrm{~nm})$ was deposited to provide a diffusion barrier and to prevent the formation of intermetallic Ti-Au compounds, and a final gold layer $(150 \mathrm{~nm})$ was deposited. Next, electrodes and metal tracks were patterned via selective wet etching baths and, finally, a $1.9 \mu \mathrm{m}$ SU-8 passivation layer was spin-coated to define the electrode active area and the connecting pads. Each individual sawed needle was fixed on a printed circuit board and wire bonding was used for electrical connections.

\section{Oxygen measurements}

The DO-MEA sensor operation was based on amperometric measurement principles (Mottola 1978). Oxygen measurements were conducted with an electrochemical system consisting of an 8-channel potentiostat (1010C Electrochemical Analyzer, CH-Instruments, USA) and a conventional three-electrode cell. An Ag/AgCl (3M KCl) electrode (Metrohm, Germany) served as reference electrode (RE), a Platinum ring electrode (Metrohm, Germany) was used as counter electrode (CE) and the sensing electrodes served as working electrodes (WE). 
The sensor was polarized, using the electrochemical setup, at a potential at which oxygen was reduced on the sensing electrodes surface. The optimal value of the polarization voltage was determined by linear sweep voltammetry analysis and, in accordance with Paliteiro (1994), a -850 mV potential was used. The polarization current of each gold microelectrode was used to quantify the DO concentration.

Thus, the DO-MEA sensor allowed for an 8-point DO concentration profile of $1 \mathrm{~mm}$ depth via a single measurement.

DO-MEA sensor calibration and characterization

The use of the DO-MEA sensor to monitor the DO within biofilms required a series of operations in order to optimize and characterize its response. Prior to DO-MEA calibration, electrode activation was necessary. It was found that sensor immersion in a solution of 75\% v/v $50 \mathrm{mM} \mathrm{KOH}$ and 25\% v/v $\mathrm{H}_{2} \mathrm{O}_{2}$ (Fischer et al. 2009) was the most suitable method of gold cleaning for the DO-MEA sensor.

After activation, the DO-MEA sensor was calibrated in the $0-8 \mathrm{mg} \mathrm{DO} \cdot \mathrm{l}^{-1}$ range. The calibration procedure consisted of adjusting the DO concentration, controlled with an oxygen probe (OXI 325, WTW, Germany), by bubbling a mixture of nitrogen $\left(0 \% \mathrm{O}_{2}\right)$ and air $\left(21 \% \mathrm{O}_{2}\right)$ in the measuring medium. Polarization currents measured at six different DO concentrations were used to create calibration plots. Calibration data was used in the sensor characterization, revealing a linear response in the calibration range (correlation coefficients greater than 0.990 ), a sensor sensitivity of $2.41 \pm 0.08 \mathrm{nA} \cdot \mathrm{mg} \mathrm{DO}^{-1} \cdot 1$ and detection and quantification limits of $0.04 \mathrm{mg} \cdot \mathrm{l}^{-1}$ and $0.15 \mathrm{mg} \cdot \mathrm{l}^{-1}$, respectively. The DO-MEA sensor may be used in distinct mediums having a minimum ionic strength of $1 \mathrm{mS} \cdot \mathrm{cm}^{-1}$ (to ensure an optimal sensor response).

\section{Measurement of mass transport properties}

The effective diffusivity within biofilms may be determined experimentally with both limiting current (Yang and Lewandowski 1995) and apparent diffusivity microsensors (Beyenal et al. 1998; Revsbech et al. 1998). This study focused on limiting current sensors, having configurations (naked metal electrodes) that are equivalent to those of MEA sensors. Thus, the DO-MEA sensor was adapted to perform mass transport rate and effective diffusivity measurements.

Limiting current measurements 
Limiting current measurements were conducted with amperometric electrodes without silicon membranes, making them sensitive to the mass transport rate near the sensor tip. These measurements were based on the application of a potential between the electrodes and the reference system, at which the electroactive species concentration at the electrode surface is zero and the concentration gradient can no longer increase. The limiting current measurements used in mass transport rate and effective diffusivity monitoring were conducted using $\mathrm{Fe}(\mathrm{CN})_{6}{ }^{3-}$ as the electroactive substance, since it is a fully characterized species, in both physical and chemical terms (Gao et al. 1995). To prevent electromigration problems, the ferricyanide solution was prepared using $\mathrm{KCl}(0.2 \mathrm{M})$ as the supporting electrolyte.

\section{Local mass transport coefficient microsensor}

The DO-MEA sensor was adapted to a mass transport rate sensor through application of the limiting current technique (Yang and Lewandowski 1995). Limiting current sensors have been used to measure the local mass transfer coefficient to a surface (Dawson and Trass 1972) and the profiles of this coefficient within biofilms (Rasmussen and Lewandowski 1998). The technique utilized is based on the application of a potential, in the presence of $\mathrm{Fe}(\mathrm{CN})_{6}{ }^{3-}$, satisfying the limiting current conditions. This potential reduces $\mathrm{Fe}(\mathrm{CN})_{6}{ }^{3-}$, removing it from the electrode surface, creating equilibrium in the local consumption of the electroactive substance at the electrode surface (Eq. 1),

$$
J=\frac{I}{n \cdot A \cdot F}
$$

where $J$ is the flux of ferricyanide $\left(\mathrm{mol} \cdot \mathrm{m}^{-2} \cdot \mathrm{s}^{-1}\right), I$ is the polarization current (A), $A$ is the electrode area $\left(\mathrm{m}^{2}\right)$ and $n$ is the number of electrons transferred in the $\mathrm{Fe}(\mathrm{CN})_{6}{ }^{3-}$ reduction, and the mass transport of the electrolyte from the bulk solution to the electrode surface (Eq.2).

$$
J=k \cdot\left(C_{0}-C_{S}\right)
$$

Where $k$ is the mass transport coefficient $\left(\mathrm{m}^{-1} \mathrm{~s}^{-1}\right), C_{0}$ is the bulk solution concentration $\left(\mathrm{mol} \cdot \mathrm{m}^{-3}\right)$ and $C_{S}$ is the electrode surface concentration $\left(\mathrm{mol} \cdot \mathrm{m}^{-3}\right)$.

Based on this equilibrium, considering that the current generated is only affected by the local mass transport of $\mathrm{Fe}(\mathrm{CN})_{6}{ }^{3-}$, the local mass transport coefficient may be calculated from Eq. 3 . 


$$
k=\frac{I}{n \cdot A \cdot F \cdot\left(C_{0}-C_{S}\right)}
$$

\section{Effective diffusivity measurements}

The relationship between the limiting-current and effective diffusivity has been widely studied (Beyenal et al. 1998) and its correlation with ferricyanide was reported in Beyenal and Lewandowski (2002) (Eq. 4).

$$
D_{C N}=1.12 \cdot 10^{-10}+3.69 \cdot 10^{-12} \cdot\left(\frac{I}{A}\right)
$$

Where $D_{C N}$ is the effective diffusivity of ferricyanide $\left(\mathrm{m}^{2} \cdot \mathrm{s}^{-1}\right)$.

\section{Development of an aerobic heterotrophic biofilm}

Microelectrodes measurements were conducted through a biofilm grown in a flat plate bioreactor (FPB). The FPB was designed in accordance with Lewandowski and Beyenal (2007) and consisted of an open channel, manufactured in methacrylate (PMMA), $20 \mathrm{~cm}$ in length, $3.5 \mathrm{~cm}$ in width and $1.3 \mathrm{~cm}$ in depth. A peristaltic pump (MCP Standard, Ismatec, Germany) was used to feed the reactor with a nutrient solution (Dorado et al. 2012) containing glucose as the sole carbon and energy source at $13 \mathrm{~g} \cdot \mathrm{l}^{-1}$, and a second peristaltic pump (Miniplus 3, Gilson, France) served to recirculating the liquid phase through the reactor. A mixing chamber, with continuous air bubbling, was placed on the recirculation line in order to maintain the oxygen saturation level in the liquid phase at the inlet of the reactor.

The reactor, as well as all attachments, was sterilized by recirculating a 30\% NaClO solution for 1 hour and it was rinsed with distilled water prior to inoculation. It was seeded with $35 \mathrm{ml}$ of sludge $\left(2 \mathrm{~g} \mathrm{VSS} \cdot \mathrm{l}^{-1}\right.$ ) from a pilot plant bioreactor treating synthetic wastewater. The remaining volume of the reactor $(115 \mathrm{ml})$ was filled with the nutrient solution, and the reactor was operated batchwise for 24 hours, after which it began to operate continuously until a well-defined biofilm was formed on the bottom of the reactor, after approximately 3 days. During biofilm growth, flow rate and residence time were adjusted to approximately $1 \mathrm{~m} \cdot \mathrm{h}^{-1}$ and 12 hours respectively, simulating the operating conditions of a conventional biotrickling filter. Glucose concentration was measured with a refractometer (Refracto 30GS, Mettler Toledo, Switzerland) during reactor operation, and it was determined that glucose concentration did not 
limit microbial activity. Dissolved oxygen concentration and $\mathrm{pH}$ were also monitored with the DO-MEA sensor and $\mathrm{pH}-$ meter (pH25 ${ }^{+}$, Crison, USA) respectively.

Upon completion of the profiling experiments, the density of the grown biofilm was analyzed based on volatile suspended solids (VSS) analysis of a known biofilm volume (APHA). Analysis revealed a density profile across the length of the reactor. These values were used as biomass concentrations in the simulation of the DO profiles within biofilms.

\section{Biofilm modeling}

Mass transport within the biofilm may be described by diffusional mechanisms in accordance with Fick’s second law (Eq. 5).

$$
\frac{d C}{d t}=D \frac{\partial^{2} C}{\partial x^{2}}
$$

In addition, various studies (Liu and Chen 2009; Yurt et al. 2002) have demonstrated the viability of the Monod kinetic equation, widely used in suspended cultures growth models (Brouwer et al. 1998), to describe immobilized microbial growth.

Based on the study of mass transport coupled with the metabolic activity across the biofilm, it is possible to develop a model that anticipates the dynamics of the chemical species within the biofilm across time. The assumptions made when developing the model presented in the current study are listed below.

1. Oxygen is the single limiting growth factor.

2. The substrate is transported through the biofilm via one-dimensional diffusion.

3. The biofilm is considered heterogeneous across the reactor, and may be discretized into different sections.

4. Biofilm density and diffusivity are represented by their average values across the depth of each reactor section.

Based upon these assumptions and on the mass transport and biokinetics phenomena, a dynamic model

(Eq. 6) was developed to estimate oxygen evolution through biofilm using the one-dimensional diffusionreaction equation (Mitchell et al. 2004; Picioreanu et al. 1998). 


$$
D \frac{\partial^{2} C}{\partial x^{2}}=\frac{\mu_{\max }}{Y_{X / O}} \cdot \frac{C}{K_{S}+C} \cdot X+K_{d} \cdot X
$$

Where $D$ is the average oxygen diffusivity of the biofilm $\left(\mathrm{m}^{2} \cdot \mathrm{s}^{-1}\right), C$ is the oxygen concentration (mg $\left.\mathrm{DO} \cdot \mathrm{l}^{-1}\right), x$ is the biofilm depth $(\mathrm{m}), \mu_{\max }$ is the maximum specific growth rate $\left(\mathrm{s}^{-1}\right), Y_{x / o}$ is the oxygenbiomass yield (g VSS $\cdot \mathrm{mg} \mathrm{DO}^{-1}$ ), $K_{S}$ is the Monod half-saturation coefficient for oxygen (mg DO· $\mathrm{l}^{-1}$ ), $X$ is the biomass concentration (g VSS· $\mathrm{l}^{-1}$ ) and $K_{d}$ is the maintenance factor for oxygen (mg DO $\mathrm{g} \mathrm{VSS}^{-1} \cdot \mathrm{s}^{-1}$ ). According to Dorado et al. (2008) $\mu_{\max } / \mathrm{Y}_{\mathrm{x} / 0}$ may be lumped in a coefficient $\mathrm{q}_{\max }\left(\mathrm{mg} \mathrm{DO} \cdot \mathrm{g} \mathrm{VSS} \mathrm{V}^{-1} \cdot \mathrm{s}^{-1}\right.$ ).

Eq. 6 was numerically solved with Matlab $^{\oplus}$ using a numerical method for boundary value problems of ordinary differential equations. The boundary conditions used in the Eq. 6 solutions were,

$$
\begin{array}{ll}
x=0 & C=C_{\text {exp }} \\
x=x_{L} & \frac{d C}{d t}=0
\end{array}
$$

where $C_{\text {exp }}$ is the measured DO at the liquid-biofilm interface and $x_{L}$ is the biofilm thickness. Using a minimization algorithm $\mathrm{q}_{\max }, \mathrm{K}_{\mathrm{s}}$ and $\mathrm{K}_{\mathrm{d}}$ were determined.

Effective diffusivity was estimated using Eq. 5 from the oxygenation profiles recorded with the DO-MEA sensor, and it was also measured directly, using the limiting current technique. Effective diffusivity determination experiments were conducted under different flow velocities and in a single biofilm density of $21.20 \mathrm{~g} \mathrm{VSS} \cdot \mathrm{l}^{-1}$.

\section{Microprofile measurements}

DO microprofiles were obtained from a single DO-MEA measurement made by inserting the needle into the biofilm and controlling its position with respect to the biofilm surface, using a dissecting microscope (PSZBMIV-BS, World Precision Instruments, USA). RE and CE electrodes were immersed in the liquid phase. Oxygen reduction potential was applied between RE and eight of the WE, while the sensor response was recorded over a 15-second period, obtaining an 8 point snapshot profile. In the validation of the DO-MEA sensor for biofilm profiling, DO profiles were also recorded with a commercial Clark-type microsensor (OX-25, Unisense, Denmark). The Clark-type sensor was mounted on a three-dimensional 
micromanipulator (MM33-2, Unisense, Denmark) and was connected to a 4-channel amplifier (MicrosensorMultimeter, Unisense, Denmark). With the aid of the micromanipulator, the microsensor was moved through the biofilm in $50 \mu \mathrm{m}$ steps, obtaining a DO profile.

DO profiles in endogenous conditions were recorded after maintaining the reactor without substrate feeding for 24 hours. In order to confirm that the biofilm satisfied the endogenous conditions, complete glucose removal from the reactor was verified by analysis of the recirculation aqueous phase. Furthermore, the first DO profile was recorded three times, with no differences being observed between replicates. On the other hand, DO profiles under consumption conditions were measured after the reactor was fed the substrate for a 24 hour period. Profiles under both conditions were recorded for less than a one-hour period, to avoid the biofilm dynamics effect on the profile shape.

DO profiles used in biokinetics studies were first recorded because mass transfer measurements, either by oxygenation profiles or mass transport rate measurements, were found to be destructive in terms of bioactivity. This is explained by the need to inactivate the biofilm in diffusivity measurements in the first method and to use ferricyanide in the second method.

Dynamic oxygenation profiles, related to effective diffusion coefficient determination, were performed with the same setup as that used in DO profile recording, with the only difference being that the sensor signal was recorded for a 300 second period. Prior to each measurement, a deoxygenated solution was recirculated through the reactor to remove DO from the biofilm. This solution was exchanged for an oxygen saturated solution immediately prior to each measurement, obtaining reoxygenation profiles at different biofilm depths. These profiles were conducted on deactivated biofilms, where bioactivity was prevented by recirculating a $300 \mathrm{mg} \cdot \mathrm{l}^{-1} \mathrm{NaN}_{3}$ solution for 1 hour.

For mass transport rate profiles, before limiting current measurements, the nutrient solution was drained and the biofilm was washed with a $0.2 \mathrm{M} \mathrm{KCl}$ solution in order to remove nutrient solution traces. Then, the aqueous nutrient solution was replaced with a $0.25 \mathrm{mM} \mathrm{Fe}(\mathrm{CN})_{6}{ }^{3-}$ in $0.2 \mathrm{M} \mathrm{KCl}$ electrolyte solution, which was recirculated through the reactor for 4 hours in order to ensure a homogeneous $\mathrm{Fe}(\mathrm{CN})_{6}{ }^{3-}$ concentration across the biofilm.

\section{Results}

\section{DO microprofiles within the biofilm}


The suitability of the developed DO-MEA microsensor was verified by comparing the recorded profiles with those obtained with the commercial Clark-type microsensor, widely applied and validated in biofilm monitoring (Berg et al. 1998; Hibiya et al. 2004; Okabe et al. 1999). DO-MEA sensor profiles were obtained by inserting the needle into the biofilm growth in the FPB, under both endogenous and substrate consumption conditions. For purposes of these qualitative studies, it was not necessary to obtain instantaneous profiles. Therefore, to increase the number of comparable DO values, 11 point profiles were recorded, switching the measured electrodes with two consecutive measurements. The profiles recorded with the Clark-type microsensor were performed under identical operating conditions and sampling was taken at the same points on the biofilm surface. Identical positioning of the sensors was achieved using the 3-D micromanipulator.

Fig. 2 shows the DO profiles obtained from the DO-MEA sensor and the Clark-type microsensor during the validation of the novel sensor for biofilm studies. Both profiles presented the same behavior in the superficial area of the biofilm and the same trend throughout the entire biofilm. However some differences in the measured DO values were observed in the deeper biofilm zones. By examining these profiles, it is possible to determine the effective depth of the biofilm. Under endogenous conditions (Fig. 2a), oxygen decreases slowly from the biofilm-liquid interface until reaching the anaerobic limit, resulting in an effective biofilm depth of approximately $1200 \mu \mathrm{m}$. The effect of reactor substrate feeding may be observed in Fig. 2b, and it consisted of an increase in oxygen consumption within the biofilm, reaching the anaerobic limit at a depth of $600 \mu \mathrm{m}$, meaning a reduction of approximately $50 \%$ of the biofilm's effective depth.

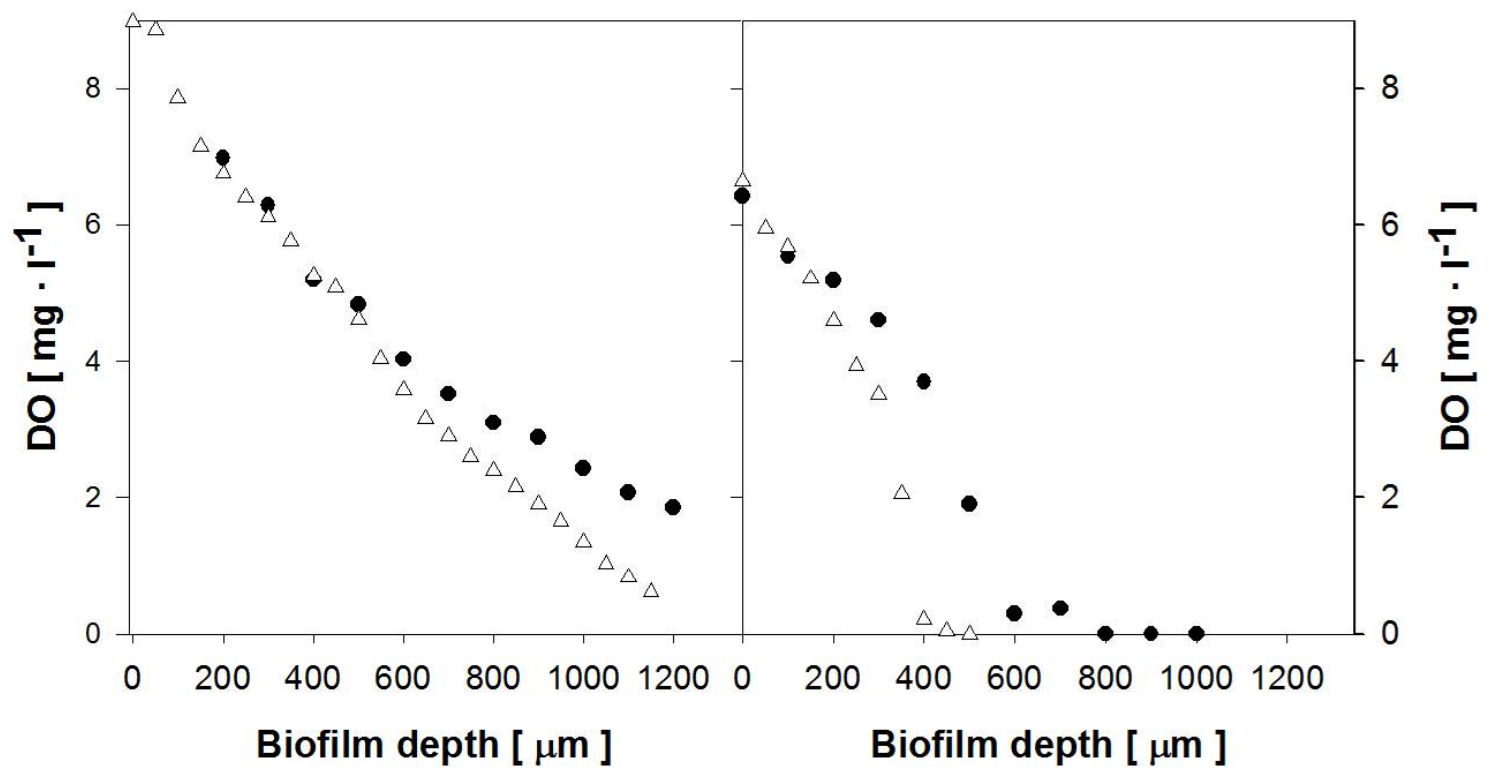


Fig. 2 DO microprofiles. (a) Microprofiles measured in endogenous conditions. (b) Microprofiles measured under conditions of substratum (glucose) consumption. MEA sensor DO measurements $(\bullet)$ were compared with Clark-type microsensor $(\Delta)$ ones.

Sensor repeatability for biofilm profiling was also analyzed. In this study, a DO profile was repeated three times (Fig. 3) at the same location in the biofilm. Profiles were recorded at 1 minute intervals, maintaining the needle immersed within the biofilm in order to reduce potential damage caused by the measurement.

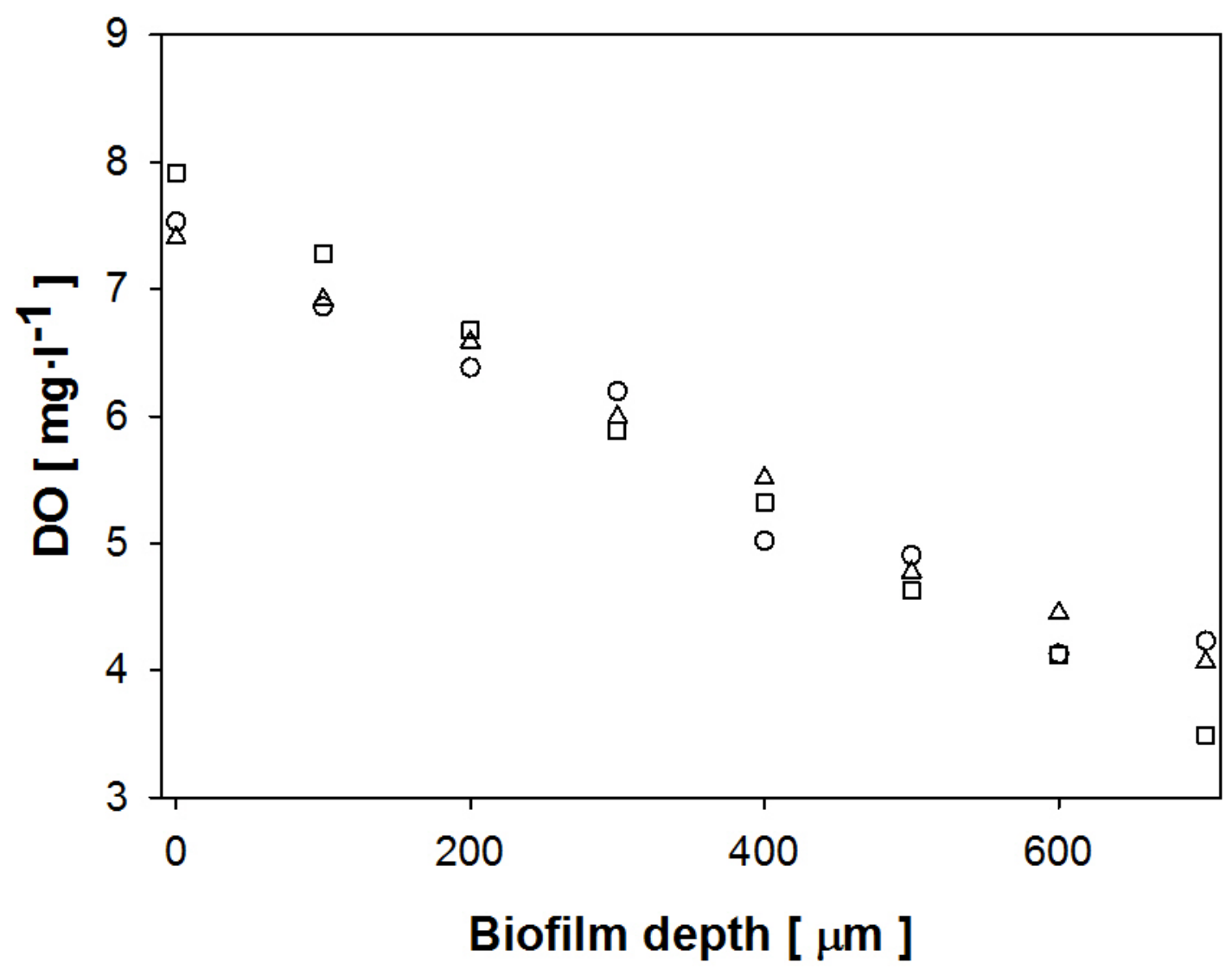

Fig. 3. DO profiles recorded at 1 minute intervals, used to analyze the DO-MEA sensor repeatability ( $\circ$ corresponds to the first, $\Delta$ to the second and $\square$ to the third recorded profile).

The profiles shown in Fig. 3 exhibited the same pattern across the entire profile with deviations in the measured oxygen values being below $0.10 \mathrm{mg} \cdot \mathrm{l}^{-1}$.

\section{Effective diffusivity estimation}




\section{Effective diffusivity estimation from oxygenation profiles}

Oxygenation profiles were recorded within the biofilm grown in the FPB. These profiles were obtained from successive DO data recording over time, made at different biofilm depths. The diffusion equation (Eq. 5) was used to simulate dynamic oxygen distribution within the biofilm. In addition, experimental data for mass transport within the biofilm equation made it possible to estimate the average effective diffusivity at the monitored section. In Fig. 4, the simulated surface and experimental profiles for a flow velocity of $9.88 \mathrm{~m} \cdot \mathrm{h}^{-1}$ are shown.

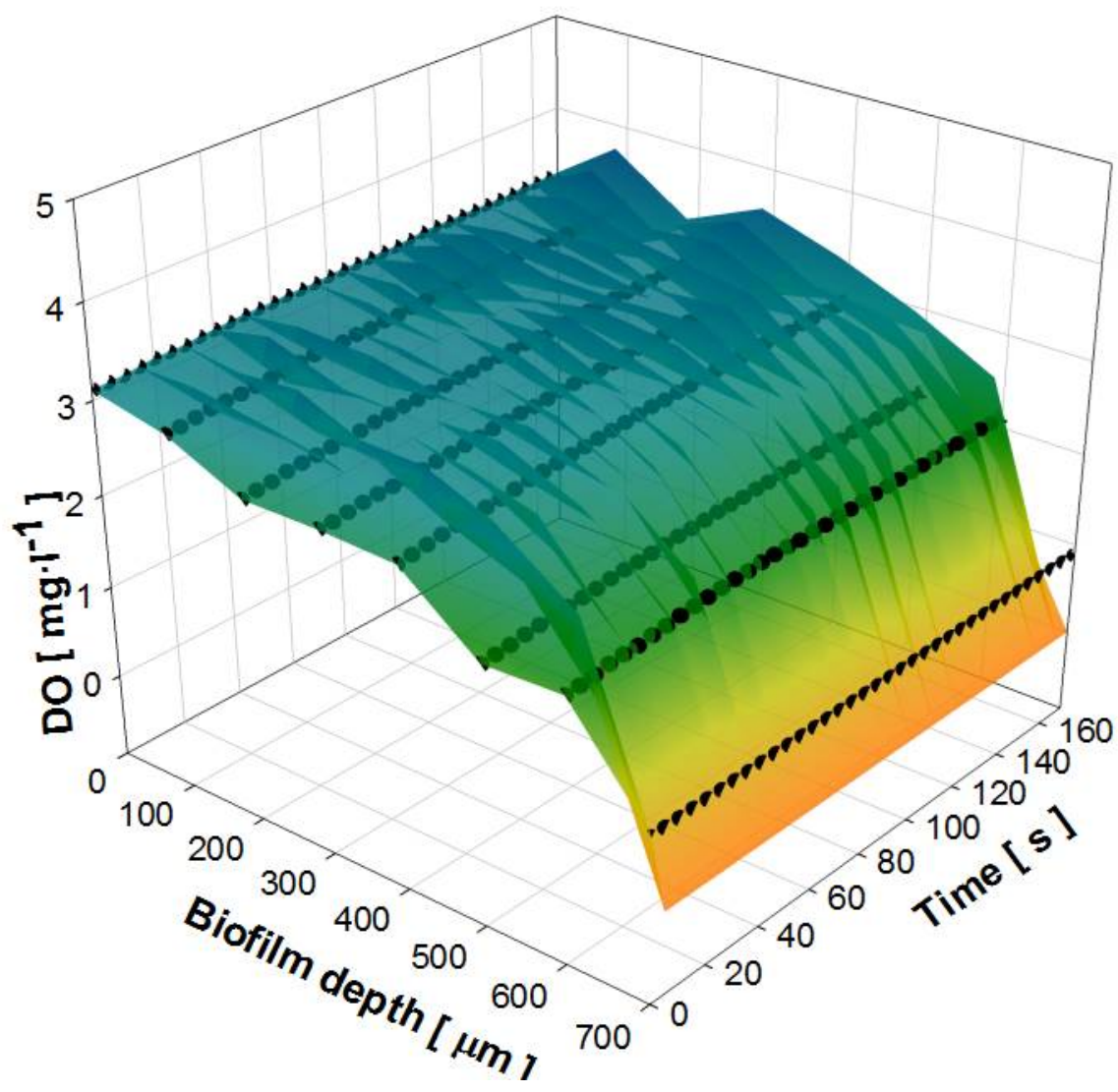

Fig. 4 Simulated (mesh) and experimental $(\bullet)$ oxygenation profiles obtained in a single measurement used in the determination of the average effective diffusivity of a biofilm section. Both represented series were recorded under a flow velocity of $9.88 \mathrm{~m} \cdot \mathrm{h}^{-1}$.

Fig. 4 reveals the oxygen distribution through the biofilm, decreasing from $3 \mathrm{mg} \mathrm{DO} \cdot \mathrm{l}^{-1}$ on the biofilm surface to $0 \mathrm{mg} \mathrm{DO} \cdot \mathrm{l}^{-1}$ at a depth of $600 \mu \mathrm{m}$. Oxygenation curves at the different depths also shown a smooth slope of approximately $1.375 \cdot 10^{-3} \mathrm{mg} \mathrm{DO} \cdot \mathrm{l}^{-1} \cdot \mathrm{s}^{-1}$. 
Since effective diffusivity depends on operational conditions, the oxygenation profiles were recorded at different flow rates. The average effective diffusivity results at flow velocities of 1.98, 3.95, 9.88 and $19.75 \mathrm{~m} \cdot \mathrm{h}^{-1}$ (typical values used in biotrickling filtration) are presented in Fig. 5.

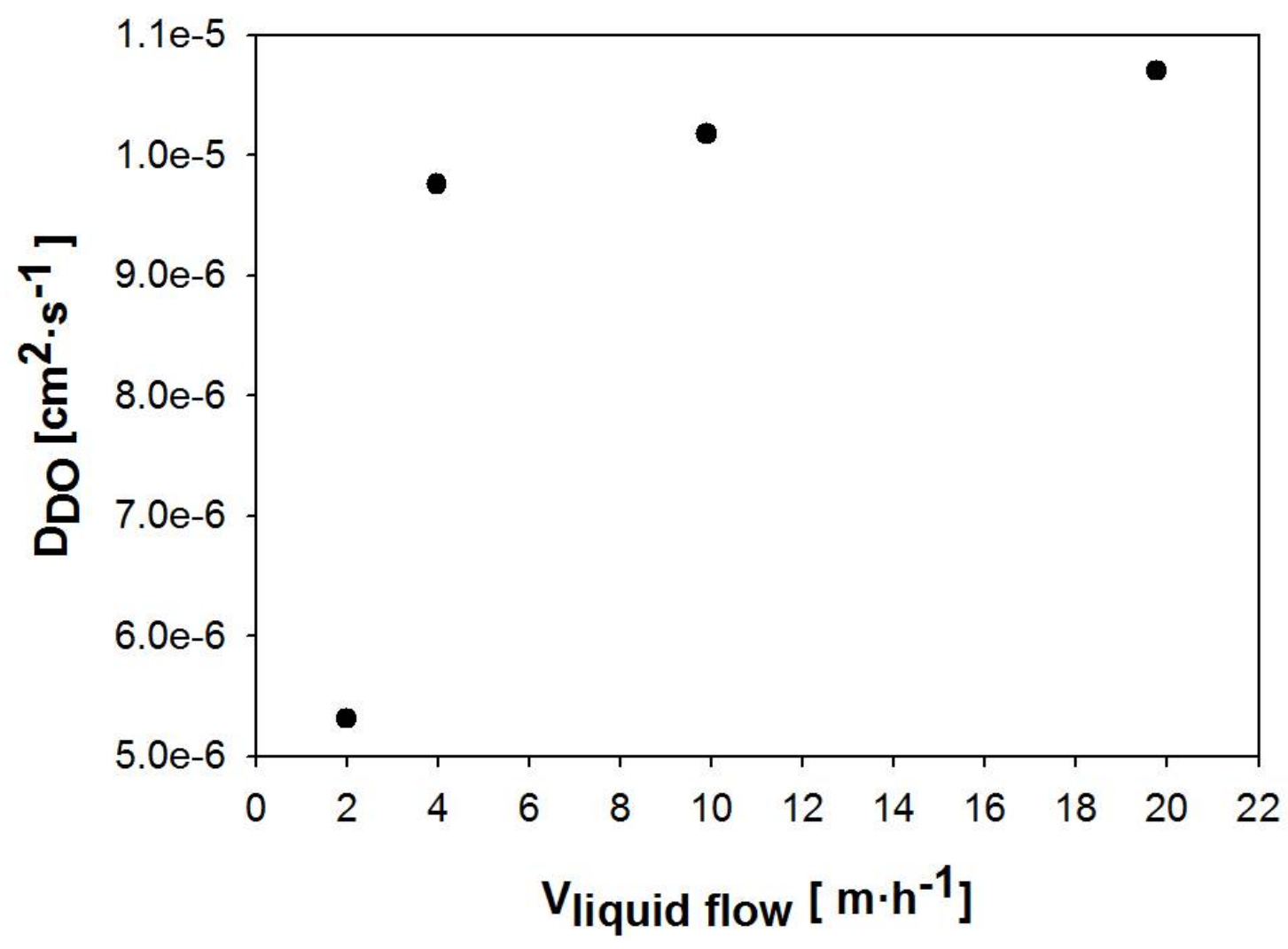

Fig. 5 Results of the average effective diffusivity $(\bullet)$ in a biofilm section, with a biofilm density of $21.20 \mathrm{~g} \mathrm{VSS}^{-1} \cdot \mathrm{l}^{-1}$, calculated from oxygenation profiles, at different flow velocities.

Figure 5 reveals that effective diffusivity depends on flow velocity. Results show that at slow flow velocities, below $2 \mathrm{~m} \cdot \mathrm{h}^{-1}$, estimated diffusivity was lower than at higher velocities, $5.32 \cdot 10^{-6} \mathrm{~cm}^{2} \cdot \mathrm{s}^{-1}$. It was also found that as of $4 \mathrm{~m} \cdot \mathrm{h}^{-1}$, the average diffusivity for a biofilm section was independent of the flow rate, varying slightly between $9.76 \cdot 10^{-5}$ and $1.07 \cdot 10^{-5} \mathrm{~cm}^{2} \cdot \mathrm{s}^{-1}$.

Effective diffusivity estimation from limiting current measurements

Before using the limiting current technique to take the effective diffusivity measurements, the appropriateness of the correlation described in Eq. 4 for the MEA sensor, under limiting-current conditions, was tested in a $25 \mathrm{mM} \mathrm{Fe}(\mathrm{CN})_{6}{ }^{3-}$ in $0.2 \mathrm{M} \mathrm{KCl}$ solution. The current measured in the solution 
was used to calculate the molecular effective diffusivity of ferricyanide in water, with Eq. $4\left(7.225 \cdot 10^{-10} \pm\right.$ $\left.5.96 \cdot 10^{-12} \mathrm{~m}^{2} \cdot \mathrm{s}^{-1}\right)$. This value was compared with that reported in Gao et al. (1995) $\left(7 \cdot 10^{-10} \mathrm{~m}^{2} \cdot \mathrm{s}^{-1}\right)$, revealing that the ferricyanide correlation was valid for use with the MEA sensor.

The ferricyanide effective diffusivity profiles within the biofilm were also measured. These results were standardized, calculating the relative effective diffusivity $\left(D_{r}\right)$ as seen in Eq. 9.

$$
D_{r}=\frac{D_{C N-B}}{D_{C N-W}}
$$

Where $D_{C N-B}$ is the effective diffusivity of ferricyanide in the biofilm and $D_{C N-W}$ is the effective diffusivity of ferricyanide in water. Based on relative effective diffusivity values, it is possible to calculate oxygen diffusivity within the biofilm, as described by Beyenal and Lewandowski (2002). The profiles were also recorded under different flow rate conditions. Figure 6 shows results for six different flow velocities in the same range as was done for the results of the oxygenation profile method.

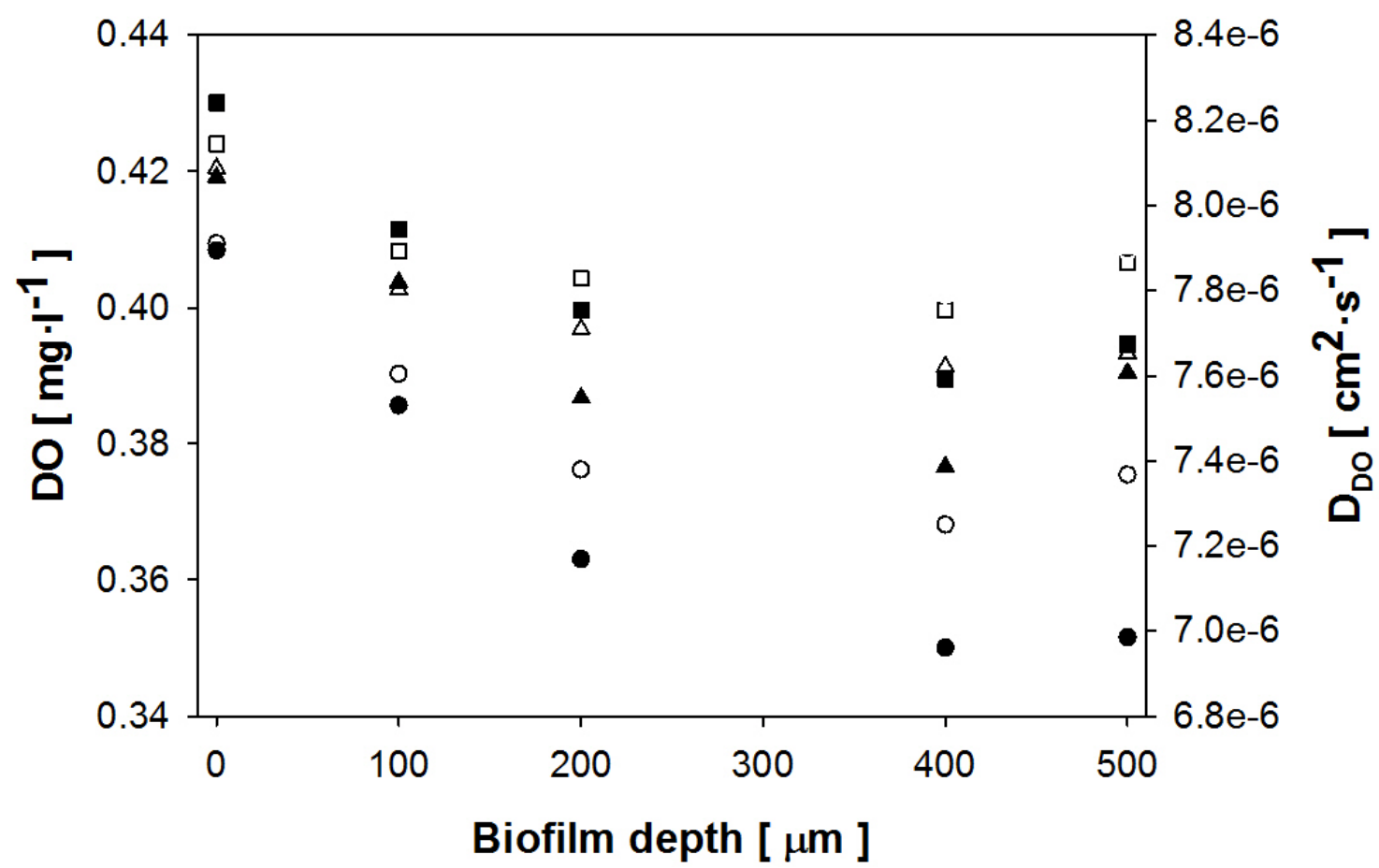

Fig. 6 Relative effective diffusivity and oxygen effective diffusivity profiles calculated by limiting-current measurements. Profiles were recorded at six different flow velocities $(1.98(\bullet), 3.10(\circ), 4.94(\boldsymbol{\Delta}) 9.88(\Delta), 17.78$ and $\left.23.70(\square) \mathrm{m} \cdot \mathrm{h}^{-1}\right)$. 
In Fig. 6 a decrease in relative diffusivity from the surface to the deeper parts of the biofilm was observed. Comparing the results of the six profiles, a smoothing in their slope was observed by increasing the liquid phase velocity. The relative diffusivity that in the slowest flow velocities ranged from 0.41at the biofilm surface, to 0.34 at the deeper parts of the biofilm, ranged only between 0.43 and 0.41 at the highest flow velocities. In addition, an increase in liquid phase velocity again caused an increase in the effective diffusivity.

\section{Biokinetics estimation}

The biokinetic parameters, reflected in Eq. 6, were determined experimentally from the biofilm DO profiles. Determination of two parameter types, maintenance coefficient for oxygen and growth parameters, required the measurement of DO profiles under both endogenous and substrate consumption

conditions. The profiles were recorded at a flow velocity of $9.88 \mathrm{~m} \cdot \mathrm{h}^{-1}$, using the average effective diffusivity in a section determined through the oxygenation profiles. This diffusivity, presented in Fig. 5, was selected due to the fact that Eq. 6 considers the average effective diffusivity of each biofilm section. In order to study biofilm heterogeneity, the DO profiles, under both conditions, were recorded at the inlet, the middle and the outlet sections of the reactor.

\section{Maintenance coefficient}

DO profiles, recorded without substrate feeding (endogenous conditions), are displayed in Fig. 7. These profiles were used to experimentally determine the maintenance coefficient for oxygen. The $K_{d}$ parameter was calculated by adjusting the recorded profiles with the simulated ones, removing the substrate consumption term from the diffusion-reaction equation. 


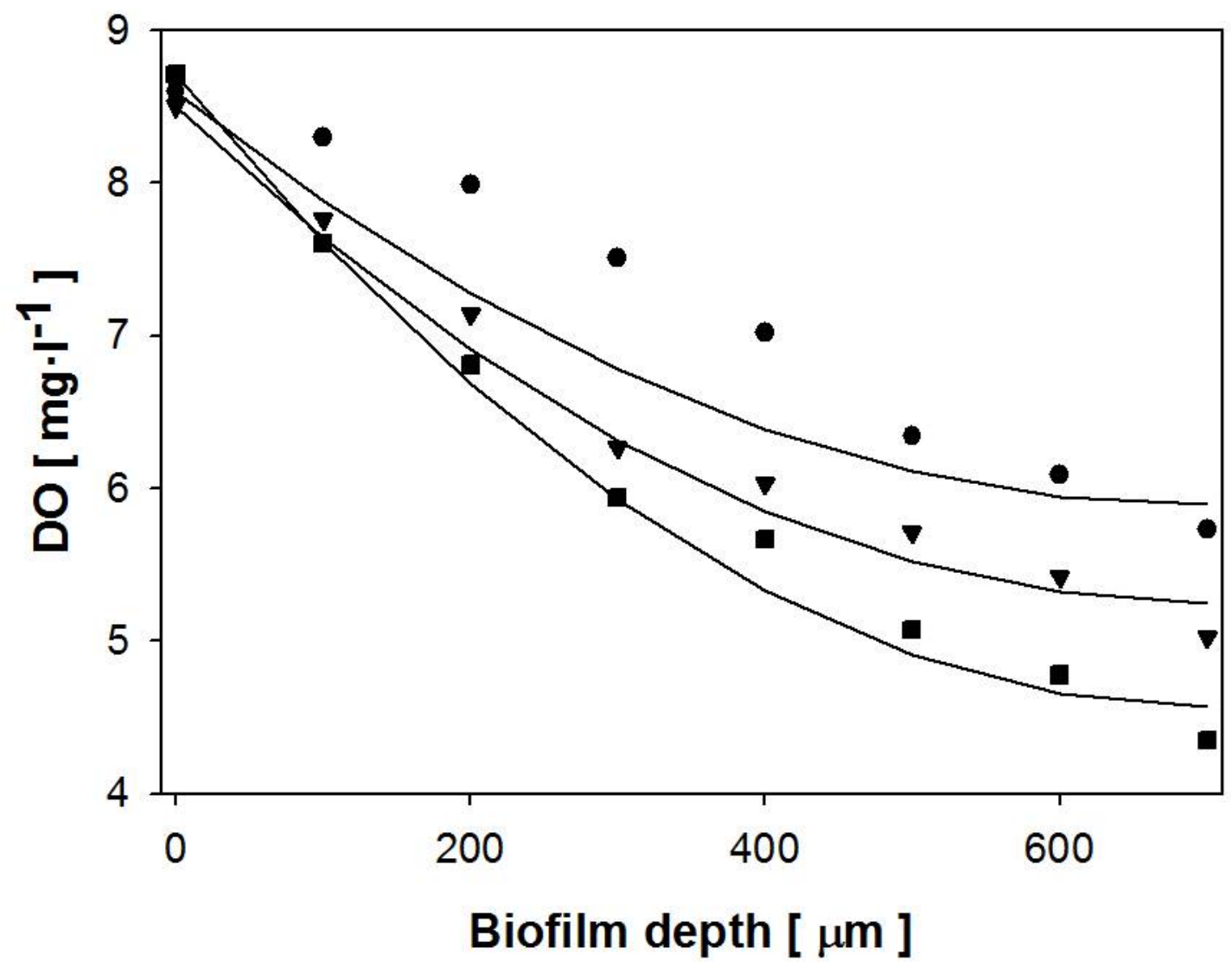

Fig. 7 DO profiles recorded under endogenous conditions used to determine the maintenance coefficient for oxygen at different points on the surface of the biofilm ( $\bullet$ corresponds to a profile recorded at the entry of the reactor, corresponds to a profile recorded in the middle of the reactor and $\mathbf{a}$ corresponds to a profile recorded at the output of the reactor).

The three profiles presented similar DO concentrations at the biofilm-liquid interface. In general, data adjustment to the model is quite good and only a few discrepancies are seen at the reactor inlet. Although the three profiles displayed similar trends, some differences may be seen, in particular, those caused by biofilm heterogeneity across the bioreactor. The parameters calculated from these profiles are presented in table 1.

The differences between the profiles observed in Fig. 7 results in substantial differences in $K_{d}$ determination, shown in table $1 . \mathrm{K}_{\mathrm{d}}$ range from $5.58 \cdot 10^{-4}$ to $7.89 \cdot 10^{-4} \mathrm{~g} \mathrm{VSS} \cdot \mathrm{s}^{-1}$, meaning a variation of approximately $30 \%$ across the biofilm. The quality of the data fitting was evaluated through a statistical study based on a paired t-Student's test. The t-test executed on each profile yielded experimental t-values of 1.8 at the inlet, 1.12 at the middle and 1.31 at the outlet of the reactor. A t-value of 2.36 at $5 \%$ level of 
significance for 7 degrees of freedom indicates that the differences between measured and predicted profiles are not significant.

\section{Growth biokinetic parameters}

DO profiles recording was repeated while feeding the reactor under non-limiting substrate (carbon source) conditions. Under consumption conditions, using calculated values for the oxygen maintenance coefficient and simulated profiles based on the diffusion-reaction equation, growth kinetics parameters were calculated (Fig.8).

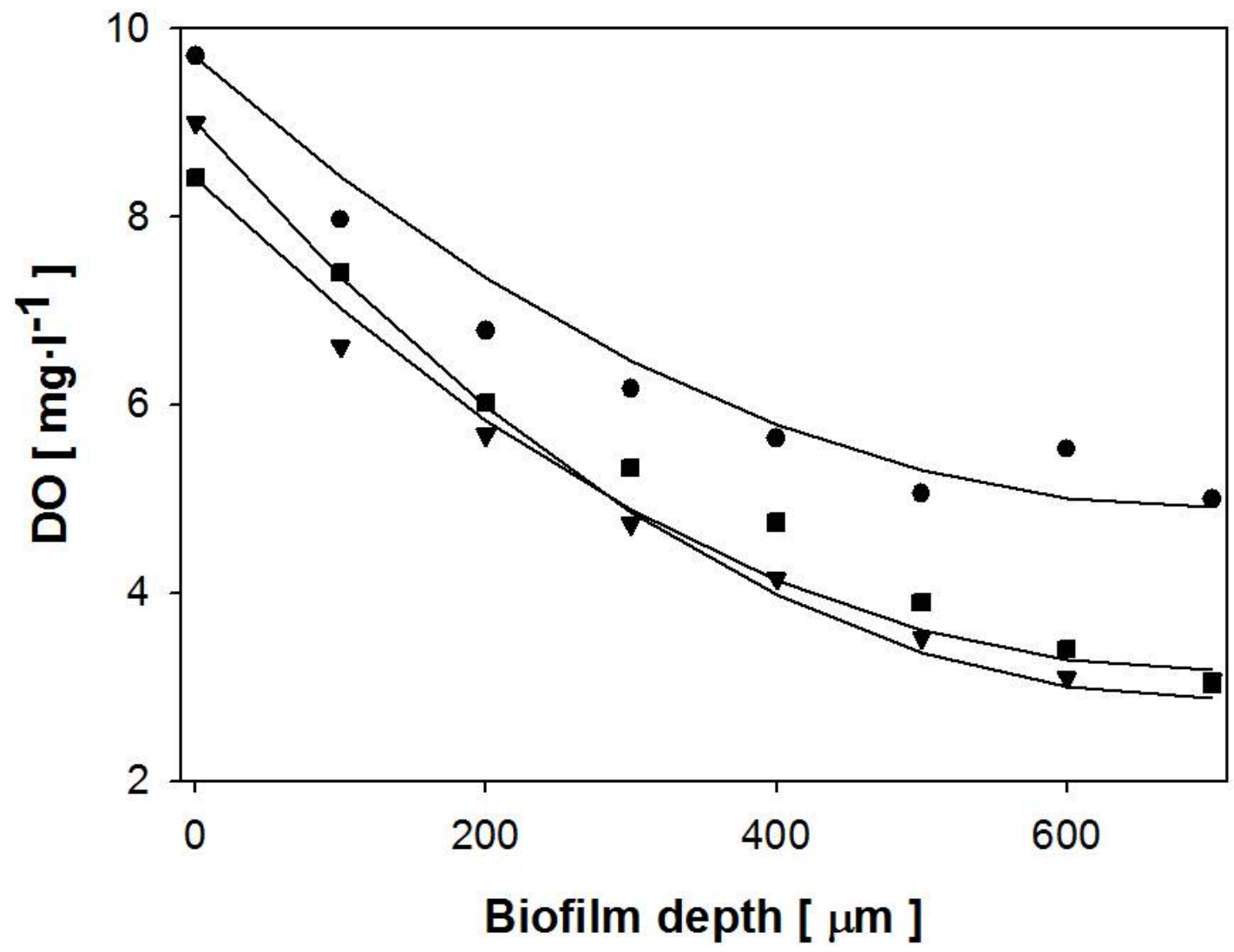

Fig. 8 DO profiles recorded under substrate consumption conditions used to determine the growth parameters, $q_{\max }$ and $\mathrm{K}_{\mathrm{S}}$ at different points on the surface of the biofilm (• corresponds to the profile recorded at the reactor inlet, corresponds to the profile recorded in the middle of the reactor and $\mathbf{a}$ corresponds to the profile recorded at the outlet of the reactor).

In contrast to the previous DO profiles (Fig. 7), the profiles presented in Fig. 8 revealed differences in the interface DO concentration. In this case, the behavior of the profiles within the biofilm also revealed 
some differences caused by the heterogeneity of the biofilm. These differences are evidenced in the biokinetic parameters estimated from these profiles, shown in Table 1.

Clearly different behavior was found for the two parameters shown in table 1, with particularly large differences being seen in the calculated $\mathrm{q}_{\max }$ values and smaller differences being revealed in the calculated $\mathrm{K}_{\mathrm{S}}$ values. The $\mathrm{q}_{\max }$ parameter ranges from $5.95 \cdot 10^{-4}$ to $8.95 \cdot 10^{-4} \mathrm{mg} \mathrm{DO} \cdot \mathrm{g} \mathrm{VSS} \mathrm{V}^{-1} \cdot \mathrm{s}^{-1}$, resulting in differences of the $34 \%$ of its value across the reactor. On the other hand, the differences in the $\mathrm{K}_{\mathrm{S}}$ were lower, ranging from 0.675 to $0.77 \mathrm{mg} \mathrm{DO} \cdot \mathrm{l}^{-1}$, a $12 \%$ variation of its value across the reactor. The data fitting performed for the growth biokinetic parameters estimation were also evaluated by a paired tStudent test. With the statistical study t-values of 1.12, 1.93 and 0.59 were calculated for the profiles at the inlet, the middle and the outlet of the reactor respectively. The same t-values used in the previous study revealed that the differences between measured and predicted profiles are neither statistically significants.

\section{Discussion}

The DO-MEA sensor was tested in biofilms, presenting similar behavior to other DO microsensors based on MEMS technology (Lee et al. 2007; Liu and Chen 2009). Furthermore, DO-MEA sensor operation was compared to that of commercial Clark-type microsensor for biofilm monitoring (Fig. 2). Results revealed that the profile recorded with the DO-MEA sensor displayed similar trends as the Clark-type microsensor profiles, with some differences being found in the measured oxygen values at the deeper areas of the biofilm. These differences were the result of the DO-MEA dimensions (500 $\mu \mathrm{m}$ thickness as opposed to $25 \mu \mathrm{m}$ of the Clark-type microsensors tips). The increased thickness of the needle led to disturbances in biofilm structure, permitting entry of liquid between the sensor and the biofilm, and resulting in misleading higher DO concentration measurements. Newly designed sensors should have smaller tips in order to overcome this limitation without reducing DO-MEA sensor sensitivity.

Taking into account the disturbances caused by DO-MEA sensor thickness and the good sensor repeatability for biofilm profiling, as revealed in Fig. 3, the biokinetic parameters at the different locations in the biofilm were estimated from a single profile.

It is also important to note that the DO-MEA sensor, with its special design, offers the possibility of conducting DO profiles within biofilms with a single measurement, eliminating the need for a 
micromanipulator and thereby significantly simplifying the procedure. Therefore, considering the differences between Clark-type and MEMS-based microelectrodes, the DO-MEA sensor performance may be considered appropriate for multipoint data collection in biofilms. However, problems resulting from the DO-MEA sensor dimensions should be addressed in future studies through the fabrication of the sensor on a polymer, instead of on a Pyrex wafer, with a maximum thickness of $50 \mu \mathrm{m}$ (Guimerà et al. 2013).

As previously discussed, many efforts have focused on the quantification of mass transport properties across biofilms. These studies have primarily attempted to determine mass transport parameters, both mass transport rate and effective diffusivity, from DO measurements taken with microsensors (Hille et al. 2009; Ning et al. 2012) or from direct measurements of mass transport using specific microsensors. The DO-MEA sensor was used to determine the average effective diffusivity of a biofilm section through adjustment of the measured oxygenation profiles in a dynamic model simulation. This procedure is quite promising as it allows for the obtaining of an effective diffusivity profile across the reactor while considering biofilm heterogeneity. Also, considering the tedious experimental procedure required for similar studies using Clark microsensors (Beuling et al. 2000; Bishop et al. 1995; Fu et al. 1994), the possibility of reducing it to a single measurement should be considered a major improvement. The reliability of the diffusivity estimations was analyzed from similar studies. In Fu et al. (1994) and (Bishop et al. 1995) DO relative diffusivity was characterized in aerobic heterotrophic biofilms having a thickness of $900 \mu \mathrm{m}$, obtaining an average diffusivity approximately 0.55 times the effective diffusivity of oxygen in water ( $\left.\mathrm{D}_{\mathrm{DO}-\mathrm{w}}\right)$. Based on reported values of $\mathrm{D}_{\text {DO-w }}$ (Perry and Green 1997$)$ it was possible to verify the reliability of the transient method for the measurement of diffusivity coefficient with microelectrodes in natural, inactivated biofilms.

The DO-MEA sensor was successfully adapted to perform diffusivity measurements through the limiting current technique, finding that the relative effective diffusivity decreases from the surface to the deeper parts of the biofilm. This was described by Zhang and Bishop (1994) to result from the increased cell concentration in the deeper areas of the biofilm, resulting in a decrease in porosity and, consequently, in diffusivity. Therefore, these profiles were extremely useful as they permitted an increased knowledge of the heterogeneity of biofilms. Thus they may eventually be correlated with biomass density profiles, permitting their characterization (Beyenal et al. 1998). This technique may be further extended to the 
determination of biomass density profiles in packed bioreactors such as biofilters and biotrickling filters. The relative diffusivity profiles presented in Fig. 6 were compared to similar studies performed with specific limiting-current microsensors (Beyenal 2000). In this study, with a flow velocity of $17 \mathrm{~m} \cdot \mathrm{h}^{-1}$, the relative diffusivity from the surface to the deeper parts of the biofilm extended between 0.44 and 0.39 , consistent with the results of Beyenal (2000) in which relative diffusivity ranged from 0.45 and 0.41 at a flow velocity of $15 \mathrm{~m} \cdot \mathrm{h}^{-1}$. Therefore the MEA sensor appears to be well suited to the limiting current technique, improving upon the current microsensors by permitting the measurement of DO profiles, mass transport coefficients and effective diffusivity with a single device.

The dependence of effective diffusivity on flow velocity was examined, as revealed in Fig. 5 and Fig. 6. Results shown in Fig. 6 reveal that biofilm the effect of heterogeneity on diffusion through the biofilm decreases as flow velocity is increased. This fact, reflected in the smoothing of the effective diffusivity profiles, indicates that the biofilm effective diffusivity may be approximated as an average effective diffusivity under turbulent conditions, although this is not the case for laminar flows where the relative diffusivity from the surface to the deeper parts of the biofilm ranges from 0.455 to 0.345 . This conclusion may be verified by the results presented in Fig. 5 . These results reveal that up to $4 \mathrm{~m} \cdot \mathrm{h}^{-1}$, the effective diffusivity increases slightly, as a result of biofilm effective diffusivity homogenization, while at slow flow velocities, the value is considerably lower, due to the increase of the effective diffusivity variation within the biofilm under these conditions.

The recording of DO profiles under both endogenous and substrate consumption conditions permit the obtaining of biokinetic parameter distributions across the biofilm. Results reveal that along the bioreactor, the maintenance coefficient for oxygen ranged from 2.01 to $2.84 \mathrm{mg} \mathrm{DO} \cdot \mathrm{g} \mathrm{VSS}^{-1} \cdot \mathrm{h}^{-1}, \mathrm{q}_{\max }$ varied from 2.14 to $3.22 \mathrm{mg}$ DO $\cdot \mathrm{g} \mathrm{VSS}^{-1} \cdot \mathrm{h}^{-1}$ and $\mathrm{K}_{\mathrm{S}}$ was between 0.675 and $0.77 \mathrm{mg} \cdot \mathrm{l}^{-1}$. The oscillations in the calculated $\mathrm{Kd}$ and $\mathrm{q}_{\max }$ values are larger due to the fact they contain the biomass yield term which is associated with the amount of biomass. Therefore, the heterogeneity of the biofilm clearly impacts this value. It was also observed that the biokinetic parameter distribution across the reactor does not follow the anticipated trend. More active and denser biofilm was expected to be found at the reactor inlet, where substrate concentration is higher. However, in flat plate reactors, hydrodynamics impacts biofilm structure and activity (Lewandowski and Beyenal 2007). The flow velocity causes a shear stress gradient on the biofilm across the reactor, producing a greater inverse effect on biofilm structure than initially 
expected. This was verified during the analysis of biofilm density, where thicker and denser biofilm sections were found at the outlet of the reactor. These distributions serve to highlight biofilm heterogeneity, revealing the importance of including this concept in biofilm modeling.

(Zhou et al. 2012) and Yurt et al. (2003) grew heterotrophic biofilms in order to quantify the biokinetic parameters. However, differences in operating condition limit results comparison and only a qualitative discussion of these results is possible. In Zhou et al. (2012) the biokinetic parameters were estimated without taking into account the heterogeneity of the biofilm, however, the results were reported as an average of the estimated values from different DO profiles, clearly demonstrating the existence of biofilm heterogeneity. In this study, $\mathrm{q}_{\max }$ variations across the biofilm (from 9 to $11 \mathrm{mg} \mathrm{DO} \cdot \mathrm{g} \mathrm{VSS}^{-1} \cdot \mathrm{h}^{-1}$ ), approximately $20 \%$, were comparable to the $22 \%$ variations (from 2.14 to $3.22 \mathrm{mg} \mathrm{DO} \cdot \mathrm{g} \mathrm{VSS}^{-1} \cdot \mathrm{h}^{-1}$ ) found in the current study. They also presented a $\mathrm{K}_{\mathrm{s}}$ with a $10 \%$ variability (between 0.45 and $0.5 \mathrm{mg} \cdot \mathrm{l}^{-1}$ ) also quite similar to that presented in this work (ranging a $12 \%$ between 0.675 and $0.77 \mathrm{mg} \cdot \mathrm{l}^{-1}$ ). The same can be said for the oxygen maintenance coefficient which is also consistent with the values presented for both attached growth systems (Zhou et al. 2012) and suspended growth microorganisms (Yurt et al. 2002).

Thus, the methodology described in this current work represents progress in biofilm research, permitting the study and characterization of mass transport and biokinetics processes through in situ measurements while taking biofilm heterogeneity into consideration. This tool is of particular interest as it may be used in dynamic model validation, describing biofilm functioning without the need for destructive measurements.

\section{Acknowledgements}

This work has been founded by projects DPI2011-28262-C04 and CTM2012-37927-C03/FEDER, financed by the Ministerio de Economía y Competitividad (Spain). AM gratefully acknowledges an FPI2012 pre-doctoral scholarship, (it funded her PhD studies at Universitat Autònoma de Barcelona), and

XG also acknowledges an FPI-UPC pre-doctoral scholarship, both from Ministerio de Economía y Competitivdad (Spain).

\section{References}

APHA Standard methods for the examination of water and wastewater, Edition 20. 1998. 
Berg P, Risgaard-petersen N, Silkeborg D- (1998) Interpretation of measured concentration profiles in sediment pore water - PI-. 1500-1510.

Beuling EE, van Den Heuvel JC, Ottengraf SP (2000) Diffusion coefficients of metabolites in active biofilms. Biotechnol Bioeng 67:53-60.

Beyenal H (2000) Combined effect of substrate concentration and flow velocity on effective diffusivity in biofilms. Water Res 34:528-538. doi: 10.1016/S0043-1354(99)00147-5

Beyenal H, Lewandowski Z (2002) Internal and External Mass Transfer in Biofilms Grown at Various. 55-61.

Beyenal H, Tanyolaç A, Lewandowski Z (1998) Measurement of local effective diffusivity in heterogeneous biofilm. Water Sci Technol 38:171-178.

Bishop P, Zhang T, Fu Y (1995) Effects of biofilm structure, microbial distributions and mass transport on biodegradation processes. Water Sci Technol 31:143-152. doi: 0273-1233(95)00162-X

Bonilla D, Mallén M, de la Rica R, Fernández-Sánchez C, Baldi A (2011) Electrical readout of protein microarrays on regular glass slides. Anal Chem 83:1726-31. doi: 10.1021/ac102938z

Brouwer H, Klapwijk a., Keesman KJ (1998) Identification of activated sludge and wastewater characteristics using respirometric batch-experiments. Water Res 32:1240-1254. doi: 10.1016/S0043-1354(97)00334-5

Del Campo FJ, Abad L, Illa X, Prats-Alfonso E, Borrisé X, Cirera JM, Bai H-Y, Tsai Y-C (2014) Determination of heterogeneous electron transfer rate constants at interdigitated nanoband electrodes fabricated by an optical mix-and-match process. Sensors Actuators B Chem 194:86-95. doi: 10.1016/j.snb.2013.12.016

Del Campo FJ, Ordeig O, Vigués N, Godino N, Mas J, Muñoz FX (2007) Continuous measurement of acute toxicity in water using a solid state microrespirometer. Sensors Actuators B Chem 126:515521. doi: 10.1016/j.snb.2007.03.038

Chiu ZC, Chen MY, Lee DJ, Tay ST, Tay JH, Show KY (2006) Diffusivity of Oxygen in Aerobic Granules. doi: 10.1002/bit

Dawson DA, Trass O (1972) Mass transfer at rough surfaces. Int J Heat Mass Transf 15:1317-1336.

Dorado AD, Baeza J a., Lafuente J, Gabriel D, Gamisans X (2012) Biomass accumulation in a biofilter treating toluene at high loads - Part 1: Experimental performance from inoculation to clogging. Chem Eng J 209:661-669. doi: 10.1016/j.cej.2012.08.018

Dorado AD, Baquerizo G, Maestre JP, Gamisans X, Gabriel D, Lafuente J (2008) Modeling of a bacterial and fungal biofilter applied to toluene abatement: Kinetic parameters estimation and model validation. Chem Eng J 140:52-61. doi: 10.1016/j.cej.2007.09.004

Fischer LM, Tenje M, Heiskanen AR, Masuda N, Castillo J, Bentien A, Émneus J, Jakobsen MH, Boisen A (2009) Gold cleaning methods for electrochemical detection applications. Microelectron Eng 86:1282-1285. doi: 10.1016/j.mee.2008.11.045

Fu YC, Zhang TC, Bishop PL (1994) Determination of effective oxygen diffusivity in biofilms grown in a completely mixed biodrum reactor. Water Sci. Technol. Pergamon Press Inc, pp 455-462

Gabriel G, Erill I, Caro J, Gómez R, Riera D, Villa R, Godignon P (2007) Manufacturing and full characterization of silicon carbide-based multi-sensor micro-probes for biomedical applications. Microelectronics J 38:406-415. doi: 10.1016/j.mejo.2006.11.008 
Gao X, Lee J, White HS (1995) Natural Convection at Microelectrodes. Anal Chem 67:1541-1545. doi: 10.1021/ac00105a011

Godino N, Dávila D, Vigués N, Ordeig O, del Campo FJ, Mas J, Muñoz FX (2008) Measuring acute toxicity using a solid-state microrespirometer. Sensors Actuators B Chem 135:13-20. doi: 10.1016/j.snb.2008.06.056

Guimera A, Gabriel G, Plata-Cordero M, Montero L, Maldonado MJ, Villa R (2012) A non-invasive method for an in vivo assessment of corneal epithelium permeability through tetrapolar impedance measurements. Biosens Bioelectron 31:55-61. doi: 10.1016/j.bios.2011.09.039

Guimerà A, Illa X, Traver E, Plata-Cordero M, Yeste J, Herrero C, Lagunas C, Maldonado MJ, Villa R (2013) Flexible probe for in vivo quantification of corneal epithelium permeability through noninvasive tetrapolar impedance measurements. Biomed Microdevices 15:849-58. doi: 10.1007/s10544-013-9772-x

Hibiya K, Nagai J, Tsuneda S, Hirata A (2004) Simple prediction of oxygen penetration depth in biofilms for wastewater treatment. Biochem Eng J 19:61-68. doi: 10.1016/j.bej.2003.10.003

Hille a, Neu TR, Hempel DC, Horn H (2009) Effective diffusivities and mass fluxes in fungal biopellets. Biotechnol Bioeng 103:1202-13. doi: 10.1002/bit.22351

Kim S, Deshusses MA (2003) Development and Experimental Validation of a Conceptual Model for Biotrickhg Ffltration of H2S. 119-128.

Lee J-H, Lim T-S, Seo Y, Bishop PL, Papautsky I (2007) Needle-type dissolved oxygen microelectrode array sensors for in situ measurements. Sensors Actuators B Chem 128:179-185. doi: 10.1016/j.snb.2007.06.008

Lewandowski Z, Beyenal H (2007) Fundamentals of biofilm research. 452.

Liu S, Chen Y (2009) Measurement of Dissolved Oxygen and Its Diffusivity in Aerobic Granules Using a Microelectrode Array. 43:1160-1165.

Melo LF, Frias RR (2004) Biofilm physical structure , internal diffusivity and tortuosity. 77-84.

Mitchell D a., von Meien OF, Krieger N, Dalsenter FDH (2004) A review of recent developments in modeling of microbial growth kinetics and intraparticle phenomena in solid-state fermentation. Biochem Eng J 17:15-26. doi: 10.1016/S1369-703X(03)00120-7

Mottola HA (1978) Enzymic substrate determination in closed flow-through systems by sample injection and amperometric monitoring of dissolved oxygen levels. Anal Chem 50:94-98.

Ning Y-F, Chen Y-P, Li S, Guo J-S, Gao X, Fang F, Shen Y, Zhang K (2012) Development of an in situ dissolved oxygen measurement system and calculation of its effective diffusion coefficient in a biofilm. Anal Methods 4:2242. doi: 10.1039/c2ay25132a

Okabe S, Itoh T, Satoh H, Watanabe Y (1999) Analyses of spatial distributions of sulfate-reducing bacteria and their activity in aerobic wastewater biofilms. Appl Environ Microbiol 65:5107-16.

Paliteiro C (1994) (100)-Type behaviour of polycrystalline gold towards O2 reduction. Electrochim Acta 39:1633-1639.

Perry RH, Green DW (1997) Perry’s chemical engineer's handbook, 7th editio. Mc Graw-Hill

Picioreanu C, van Loosdrecht MC, Heijnen JJ (1998) Mathematical modeling of biofilm structure with a hybrid differential-discrete cellular automaton approach. Biotechnol Bioeng 58:101-16. 
Prehn R, Abad L, Sánchez-Molas D, Duch M, Sabaté N, del Campo FJ, Muñoz FX, Compton RG (2011) Microfabrication and characterization of cylinder micropillar array electrodes. J Electroanal Chem 662:361-370. doi: 10.1016/j.jelechem.2011.09.002

Rasmussen K, Lewandowski Z (1998) Microelectrode measurements of local mass transport rates in heterogeneous biofilms. Biotechnol Bioeng 59:302-9.

Revsbech N, Jørgensen B (1986) Microelectrodes: their use in microbial ecology. Adv Microb Ecol 9:293-352.

Revsbech NP, Nielsen LP, Ramsing NB (1998) A novel microsensor for determination of apparent diffusivity in sediments. Limnol Oceanogr 43:986-992.

Rosa CD La, Yu T (2006) Development of an automation system to evaluate the three-dimensional oxygen distribution in wastewater biofilms using microsensors. Sensors Actuators B Chem 113:4754. doi: 10.1016/j.snb.2005.02.025

Schramm a, Larsen LH, Revsbech NP, Ramsing NB, Amann R, Schleifer KH (1996) Structure and function of a nitrifying biofilm as determined by in situ hybridization and the use of microelectrodes. Appl Environ Microbiol 62:4641-7.

Schwermer CU, Lavik G, Abed RMM, Dunsmore B, Ferdelman TG, Stoodley P, Gieseke A, de Beer D (2008) Impact of nitrate on the structure and function of bacterial biofilm communities in pipelines used for injection of seawater into oil fields. Appl Environ Microbiol 74:2841-51. doi: 10.1128/AEM.02027-07

Wu C-C, Yasukawa T, Shiku H, Matsue T (2005) Fabrication of miniature Clark oxygen sensor integrated with microstructure. Sensors Actuators B Chem 110:342-349. doi: 10.1016/j.snb.2005.02.014

Yang S, Lewandowski Z (1995) Measurement of local mass transfer coefficient in biofilms. Biotechnol Bioeng 48:737-44. doi: 10.1002/bit.260480623

Yurt N, Beyenal H, Sears J, Lewandowski Z (2003) Quantifying selected growth parameters of Leptothrix discophora SP-6 in biofilms from oxygen concentration profiles. Chem Eng Sci 58:4557-4566. doi: 10.1016/S0009-2509(03)00344-0

Yurt N, Sears J, Lewandowski Z (2002) Multiple substrate growth kinetics of Leptothrix discophora SP6. Biotechnol Prog 18:994-1002. doi: 10.1021/bp0255098

Zhang TC, Bishop PL (1994) Density, porosity, and pore structure of biofilms. Water Res 28:2267-2277. doi: 10.1016/0043-1354(94)90042-6

Zhou X-H, Liu J, Song H-M, Qiu Y-Q, Shi H-C (2012) Estimation of Heterotrophic Biokinetic Parameters in Wastewater Biofilms from Oxygen Concentration Profiles by Microelectrode. Environ Eng Sci 29:466-471. doi: 10.1089/ees.2010.0456

Zhu X, Suidan MT, Alonso C, Yu T, Kim BJ, Kim BR (2001) Biofilm structure and mass transfer in a gas phase trickle-bed biofilter. Water Sci Technol 43:285-93. 